\title{
Detection of circulating norovirus genotypes: hitting a moving target
}

Brenda-Lee Rooney ${ }^{1,2}$, Janice Pettipas ${ }^{2}$, Elsie Grudeski ${ }^{3}$, Oksana Mykytczuk ${ }^{4}$, Xiao-Li Pang ${ }^{5,6}$, Tim F Booth ${ }^{3}$, Todd F Hatchette ${ }^{1,2}$ and Jason J LeBlanc ${ }^{1,2^{*}}$

\begin{abstract}
Background: Although national surveillance programs are in place to monitor norovirus epidemiology, the emergence of new strains and the genetic diversity among genotypes can be challenging for clinical laboratories. This study evaluated the analytical and clinical performance characteristics of one real-time RT-PCR and two end-point RT-PCRs commonly used in microbiology laboratories.

Methods: Lower limit of detection (LOD) was determined using 10-fold dilutions of noroviruses belonging to different genotypes. The clinical performance of the real-time and end-point RT-PCRs was assessed in parallel using nucleic acids extracted from 186 stool specimens.

Results: The real-time RT-PCR was highly sensitive and specific for the detection of norovirus genotypes that are currently circulating in Canada. In contrast, the two end-point RT-PCRs displayed poor analytical sensitivity or complete failure to detect certain norovirus genotypes, which was correlated to sequence mismatches in the primer-binding sites. In an attempt to improve norovirus detection with the end-point RT-PCRs, both assays were processed concurrently and detection from either assay was considered a positive result. Concurrent testing resulted in only a modest increase in clinical sensitivity (75.0\%) compared to each assay alone (62.5\% and 71.9\%). However, the false positivity rate increased from $1.98 \%$ and $3.36 \%$ for the assays alone to $5.47 \%$ with concurrent testing.
\end{abstract}

Conclusions: This study emphasizes the benefits of a real-time method and provides support for routine surveillance to monitor norovirus epidemiology and ongoing proficiency testing to ensure detection of circulating norovirus genotypes.

Keywords: Norovirus, Proficiency testing, Quantitative RT-PCR, Epidemiology, Genotyping

\section{Background}

Noroviruses are the leading cause of acute gastroenteritis, and outbreaks are common [1,2]. Transmission occurs through the fecal-oral route and is facilitated by a low infectious dose and environmental persistence $[1,2]$. Laboratory identification of norovirus can help reduce transmission through infection control and public health interventions [2]. Since human noroviruses are uncultivable, traditional detection methods relied primarily on electron microscopy and enzyme immunoassays, both of which lack sensitivity [2-5]. RT-PCR has markedly improved the detection of noroviruses and has become the

\footnotetext{
* Correspondence: Jason.leblanc@cdha.nshealth.ca

'Dalhousie University, Halifax, Nova Scotia, Canada

${ }^{2}$ Division of Microbiology, Department of Pathology and Laboratory Medicine, Capital District Health Authority (CDHA), Dalhousie University, Halifax, Nova Scotia, Canada

Full list of author information is available at the end of the article
}

method of choice for clinical diagnosis [2]. However, the genetic diversity among noroviruses poses a particular challenge for molecular assays [6-11]. Noroviruses are classified into six genogroups, three of which cause human disease (GI, GII, and GIV) [12-14]. The two predominant genogroups, GI and GII, are further subdivided into 9 and 22 genotypes, respectively [12-14]. Strategies used to overcome norovirus diversity have included the simultaneous use of various monoplex RT-PCRs, multiplexed RT-PCRs, RT-PCRs with degenerate primers and probes [8-11,15-19].

The dynamic nature of its epidemiology poses further challenges for laboratory detection of norovirus. While genotype GII.4 is responsible for the majority of outbreaks annually, new GII.4 strains emerge every 2-3 years that replace the previously circulating pandemic strain [14,20-25]. Norovirus GII.4-2012 Sydney has recently 
emerged and replaced GII.4-2009 New Orleans worldwide [14,20-26], including the Canadian provinces of Alberta [25], British Columbia [27] and recently, Nova Scotia (unpublished data). In addition, the proportion of outbreaks associated with non-GII.4 genotypes has increased in Canada and the US, and the predominant nonGII.4 genotypes change over time [14,23,25,28]. With the diversity among norovirus genotypes and the dynamic nature of its epidemiology, this study evaluated the analytical and clinical performance of a real-time RT-PCR and two end-point RT-PCRs (EP-SR and EP-JV) commonly used for the detection of noroviruses in clinical, food and environmental laboratories [8-11,16,17,29-36].

\section{Results}

\section{Analytical sensitivity and specificity}

Each method was specific for circulating noroviruses (Table 1) and no cross-reactions occurred with various enteric pathogens. The real-time RT-PCR was able to detect all norovirus genotypes with high sensitivity (Table 1). EP-JV detected all GII.4 strains, but only a subset of non-GII.4 genotypes. EP-SR only detected GII.4 strains. For GII.4 noroviruses, real-time RT-PCR was approximately 10 -fold more sensitive than EP-JV, and 100-fold more sensitive than EP-SR (Table 1). Similarly, the LoD for different GII.4 strains were highly consistent for EP-JV. For EP-SR, only minor differences in the LoD for GII.4 strains from 2004 to 2009, but a 100 -fold decrease in sensitivity was observed for

Table 1 Limit of detection and specificity analysis

\begin{tabular}{|c|c|c|c|}
\hline \multirow[t]{3}{*}{ Genotype } & \multicolumn{3}{|c|}{$\begin{array}{l}\text { Estimated analytical sensitivity } \\
\text { [ } \log _{10}(\text { copies/ml)] }\end{array}$} \\
\hline & Real-time & EP-JV & EP-SR \\
\hline & RT-PCR & RT-PCR & RT-PCR \\
\hline \multicolumn{4}{|l|}{ Norovirus, genotype Gl } \\
\hline Gl.1 (2011) & 2.21 & $N D^{*}$ & ND \\
\hline Gl.3 (2008) & 2.27 & ND & ND \\
\hline Gl.4 (2008) & 2.67 & ND & ND \\
\hline Gl.6 (2010) & 2.11 & 5.96 & ND \\
\hline \multicolumn{4}{|c|}{ Norovirus, genotype GII (non-GIl.4) } \\
\hline Gll.1 (2011) & 2.37 & 5.54 & ND \\
\hline Gll.3 (2006) & 2.52 & ND & ND \\
\hline Gll.7 (2010) & 2.57 & ND & ND \\
\hline Gll.13 (2010) & 2.14 & ND & ND \\
\hline \multicolumn{4}{|l|}{ Norovirus, genotype GIl.4 } \\
\hline Gll.4 (2004) Den Haag & 2.20 & 3.56 & 4.55 \\
\hline Gll.4 (2006b) Osaka & 2.47 & 3.37 & 4.32 \\
\hline Gll.4 (2009) New Orleans & 2.85 & 3.53 & 4.52 \\
\hline Gll.4 (2012) Sydney & 2.61 & 3.71 & 6.62 \\
\hline
\end{tabular}

*ND signifies not detected at a minimal concentration of $10^{6} \mathrm{copies} / \mathrm{ml}$.
GII.4-2012. Reduced sensitivity was also observed with EP-JV for genotypes GI.6 and GII.1.

\section{Clinical evaluation}

The clinical sensitivity of the real-time RT-PCR and end-point RT-PCR assays (EP-JV and EP-SR) was 100\%, $71.9 \%$, and $62.5 \%$, respectively (Table 2 ). With concurrent testing of EP-JV and EP-SR, the clinical sensitivity was only modestly increased to $75 \%$ compared to each assay alone, since both EP-JV and EP-SR failed to detect 8 genotype GII.7 noroviruses (Table 3). EP-JV alone also missed a genotype GII.15 and EP-SR missed three genotype GI.6 noroviruses and one GI.3 (Table 3). With the exception of the latter, viral loads were above their LoD for all methods and the poor sensitivity of EP-JV and EP-SR was correlated to sequence mismatches in the primer-binding sites (Table 1 and Figure 1).

As non-specific amplifications were observed for both EP-JV and EP-SR, concurrent testing resulted in a reduced clinical specificity (94.8\%) compared to each method alone (98.1\% and 96.8\%, respectively) (Table 2). The false positivity rate for concurrent testing was increased to $5.47 \%$ compared to $1.98 \%$ and $3.36 \%$ for EP-JV and EP-SR alone. A two-year retrospective analysis revealed that 14 outbreaks were declared by a single EP-JV and EP-SR result where weak amplifications were noted, suggesting a possible false positivity rate of $4.8 \%$ for years 2011 and 2012 (Additional file 1: Table S2). As no differences were observed between real-time RT-PCR and the reference methods, the real-time RT-PCR was highly specific $(100 \%)$ and no false positives were observed (Tables 2 and 3).

\section{Discussion}

Genomic diversity and evolutionary change can be challenging for detection of noroviruses [2,37,38]. While detection of noroviruses using RT-PCR is far more accurate than antigen-based detection methods (i.e. EIAs), not all molecular methods are created equal [2-4]. Fortunately, most reference laboratories use a real-time RT-PCR targeting the most conserved region of the genome (ORF1ORF2 junction) and use degenerate primers and probes that can tolerate some sequence mismatches $[9,10]$ (Figure 1). In this study, this same real-time RT-PCR was able to detect diverse norovirus genotypes with analytical sensitivities consistent with values previously reported for GII.4 (2006b) (Table 1) [6]. In contrast, EP-JV and EP-SR were far less sensitive and failed to detect certain genotypes (Tables 1, 2 and 3). With hopes to enhance detection of circulating norovirus genotypes, EP-JV and EP-SR were processed concurrently and detection from either assay was considered a positive result. Concurrent testing only modestly improved clinical sensitivity (Table 2) since the majority of false negative results 
Table 2 Clinical performance characteristics compared to the modified gold standard

\begin{tabular}{|c|c|c|c|c|}
\hline \multirow[t]{2}{*}{ Method } & \multicolumn{4}{|l|}{ Clinical Parameters* } \\
\hline & Sensitivity (\%) & Specificity (\%) & Kappa & False positivity rate (\%) \\
\hline Real-time RT-PCR & $100.0(91.5-100.0)$ & $100.0(98.2-100.0)$ & $1.00(0.90-1.00)$ & 0.00 \\
\hline EP-JV & $71.9(58.6-71.9)$ & $98.1(95.3-99.5)$ & $0.76(0.58-0.84)$ & 1.99 \\
\hline EP-SR & $62.5(48.4-71.7)$ & $96.8(93.8-98.7)$ & $0.65(0.46-0.77)$ & 3.36 \\
\hline EP-JV and EP-SR & $75.0(60.3-85.5)$ & $94.8(91.7-97.0)$ & $0.70(0.52-0.82)$ & 5.47 \\
\hline
\end{tabular}

*When applicable, $95 \%$ confidence intervals are indicated in parentheses.

were common between both EP-JV and EP-SR (Table 3). Interestingly, failure of EP-JV and EP-SR to detect certain genotypes was not attributed to poor analytical sensitivity since the viral load in most clinical specimens far exceeded the LoD for each assay (Tables 1 and 3). Instead, the genotypes that failed to be detected for EP-JV (GII.7, GII.15) and EP-SR (GII.7, GI.6, and GI.3) were linked to several sequence mismatches in the primerbinding sites (Figure 1). Of note, a large norovirus outbreak in Sweden was missed due to mismatches in the primer-binding sites of JV12 and JV13 (same used for EP-JV), but were detected by another primer pair [31].

It should also be noted that real-time RT-PCR and EP-JV both detected genotype GI.3 in a specimen with a very low viral load $\left(2.47 \log _{10}\right.$ copies $\left./ \mathrm{ml}\right)$, whereas EP-JV were unable to detect this genotype at concentrations exceeding $6.0 \log _{10}$ copies $/ \mathrm{ml}$ in the specificity analysis (Tables 1 and 3). This confounding result might be explained by genetic differences between the norovirus GI.3 identified in the clinical evaluation and the one used for the specificity analysis. A 12\% nucleotide difference was noted between GI.6 and GI.7 genotypes that circulated in Canada between 2009 and 2010 compared to 2012 and 2013, suggesting that diversity among the same genotype can occur over time [24]. It is also possible that the faint amplicon detected by EP-JV was a false positive result in a specimen that was coincidently positive by real-time RT-PCR (Table 3 ).

While concurrent testing marginally increased the clinical sensitivity, a reciprocal effect was seen on the clinical specificity where the false positivity rate was higher with concurrent testing (5.47\%) than either method alone (1.98\% and $3.36 \%$ for EP-JV and EP-SR, respectively) (Table 2). Upon review of the false positive results, only faint or non-specific amplifications were noted and likely attributed to the low annealing temperature of EP-JV $\left(37^{\circ} \mathrm{C}\right)$ or lack of electrophoretic resolution between primer dimmers and the small amplicon generated with EP-SR of $123 \mathrm{bp}$. The subjectivity of gel resolution is not a problem for a properly validated real-time RTPCR $[9,10,39]$.

Following a two-year retrospective analysis of EP-JV and EP-SR results, 14 of 113 outbreaks investigated in 2011 and 2012 were declared positive by a single result where weak amplification was observed (Additional file 1: Table S2). This supports the high false positivity rate observed during the clinical evaluation (Table 2). Previous studies have demonstrated that three specimens are ideal for the detection of norovirus outbreaks using RTPCR, but excessive testing can lead to reduced specificity $[5,40,41]$. In this study, concurrent testing with multiple RT-PCRs was shown to increase the rate of false positive results, which could prematurely halt outbreak investigations caused by other enteric pathogens that might be managed differently [2].

\section{Conclusions}

Unlike the high clinical sensitivity and specificity observed with real-time RT-PCR, this study demonstrated that end-point RT-PCRs had poor accuracy for the detection of circulating norovirus genotypes. To monitor norovirus epidemiology, genotyping should be considered

Table 3 Discordant results obtained during the clinical evaluation

\begin{tabular}{|c|c|c|c|c|c|c|c|}
\hline \multirow[t]{2}{*}{ No. } & \multicolumn{3}{|l|}{ RT-PCR results } & \multicolumn{2}{|c|}{ Discordant analysis } & \multirow[t]{2}{*}{ Interpretation } & \multirow[t]{2}{*}{ Comments } \\
\hline & Real-time RT-PCR & EP-JV & EP-SR & Result & Genotype & & \\
\hline 5 & Neg. & Neg. & Pos. & Neg. & $\mathrm{N} / \mathrm{A}$ & FP (EP-SR) & Non-specific amplification \\
\hline 3 & Neg. & Pos. & Neg. & Neg. & $\mathrm{N} / \mathrm{A}$ & $F P(E P-J V)$ & Non-specific amplification \\
\hline 8 & Pos. & Neg. & Neg. & Pos. & Gll.7 & FN (EP-JV and EP-SR) & High viral loads (5.28 to $7.78 \log _{10}$ copies/ml) \\
\hline 3 & Pos. & Pos. & Neg. & Pos. & Gl.6 & FN (EP-SR) & High viral loads (5.29 to $5.74 \log _{10}$ copies/ml) \\
\hline 1 & Pos. & Pos. & Neg. & Pos. & $\mathrm{Gl} .3$ & FN (EP-SR) & Low viral load (2.47 $\log _{10}$ copies/ml) \\
\hline 1 & Pos. & Neg. & Pos. & Pos. & Gll.15 & FN (EP-JV) & High viral load (6.33 $\log _{10}$ copies/ml) \\
\hline
\end{tabular}

Abbreviations: FN false negative, FP false positive, N/A not applicable, Neg. Negative, No. number, Pos. positive. 


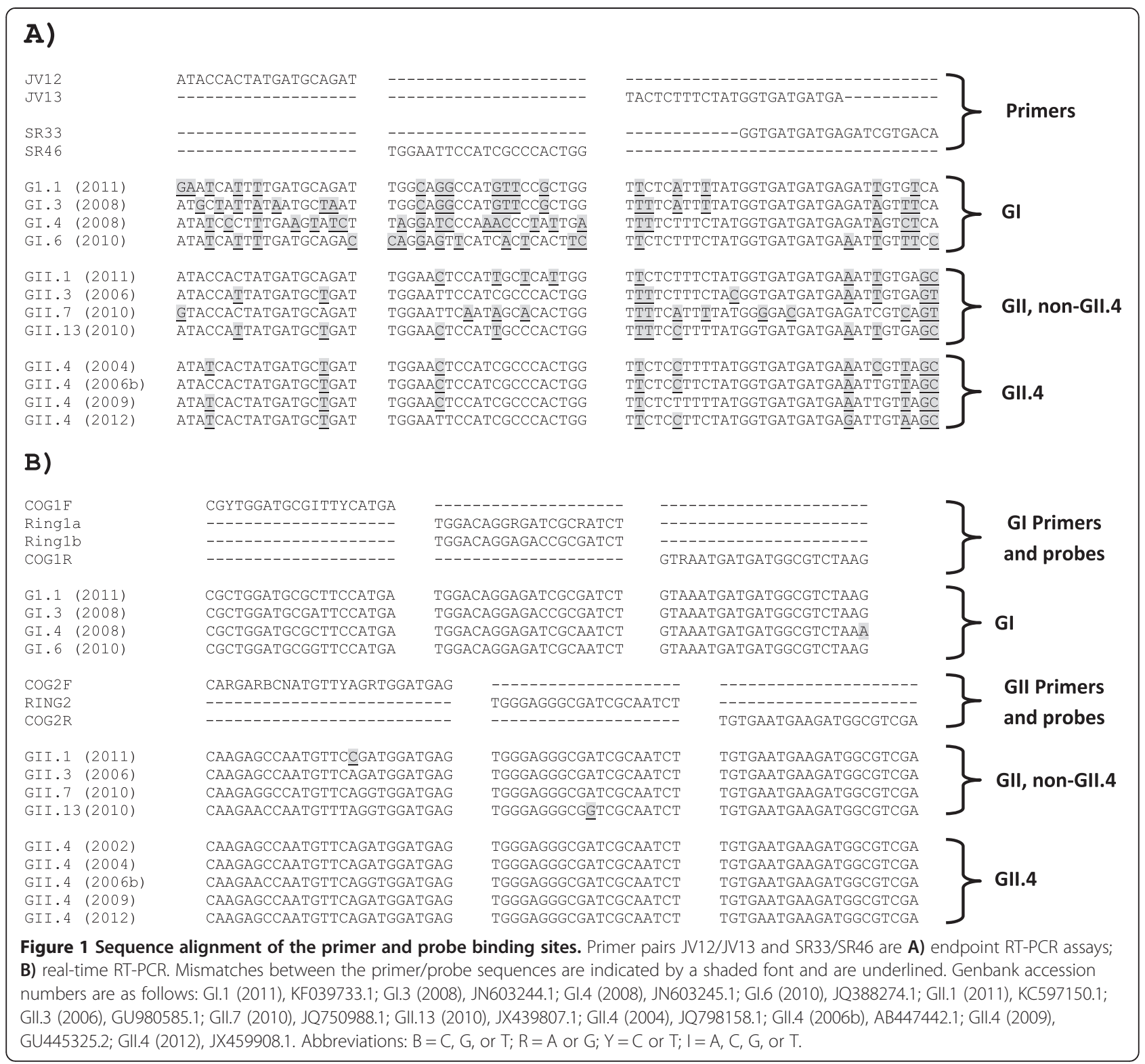

part of routine outbreak investigations when norovirus is identified as the etiological agent. Unlike well established networks like Calicinet and Noronet, norovirus surveillance in Canada is in its infancy [2,14]. Ideally, sequencing would be used to encompass the regions required for genotyping and the primer/probe-binding sites for commonly used RT-PCRs [42,43]. When sequence mismatches are identified in RT-PCR target regions or when new norovirus variants emerges, proficiency panels should be promptly disseminated to clinical laboratories to ensure accurate detection [6]. With the dynamic nature of norovirus epidemiology, this study highlights the importance of routine surveillance and ongoing proficiency testing for circulating norovirus genotypes.

\section{Materials and methods}

\section{Specimen preparation}

For the clinical evaluation, 186 stool specimens were obtained from patients with acute gastroenteritis between March 15 and June 26, 2013. Public Health outbreak investigation data was provided by the Department of Health and Wellness (Halifax, NS) (Additional file 1: Table S2). Stool slurries were prepared by transferring $200 \mu \mathrm{l}$ of stool into $500 \mu \mathrm{l}$ of PCR-grade water and centrifugation $(10,000 \times g, 10 \mathrm{~min})$. The supernatants $(140 \mu \mathrm{l})$ were subjected to a total nucleic acid (TNA) extraction on a MagNA Pure LC instrument (Roche Diagnostics, Branchburg, NJ), as recommended by the manufacturer. TNAs were eluted in a volume of $60 \mu \mathrm{l}$ and $5 \mu \mathrm{l}$ served as 
template for all molecular assays (which were processed in parallel). Primers were synthesized by Sigma Genosys (Oakville, ON) and probes by Integrated DNA Technologies (Toronto, ON).

Analytical specificity was performed using high titer total nucleic acids extracted from norovirus stool suspensions of various genotypes obtained from collaborating laboratories and concentrated suspensions (MacFarlane value of 2.0) of various enteric pathogens that included: adenovirus type 40 (ATCC VR-931); Camplobacter jejeuni (ATCC 33291); Clostridium difficile (ATCC 9689); Escherichia coli O157:H7 (ATCC 35150); Rotavirus A (ATCC VR-2018); Salmonella enterica serovar Typhymirium (ATCC 14028); sapovirus (5 clinical isolates); Shigella flexneri (ATCC 12022); Shigella dysenteriae (ATCC 13313); Yersinia enterocolitica (ATCC 9610); Vibrio cholerae (clinical isolate). To assess the LoD, 10 -fold serial dilutions of nucleic acids extracted from various norovirus genotypes were performed on specimens that had a minimum concentration of $10^{6}$ copies/ $\mathrm{ml}$. LoD was defined at a probability of $95 \%$ using Probit analysis [44] with replicate values obtained in three independent experiments $(n=9)$.

\section{End-point RT-PCRs}

EP-JV and EP-SR RT-PCR assays were performed using a OneStep RT-PCR kit (Qiagen Inc., Mississauga, ON) in $50 \mu \mathrm{l}$ reactions consisting of: $2 \mu \mathrm{l}$ enzyme mix, $1 \times$ buffer, $400 \mu \mathrm{M}$ dNTPs, 20 U RNaseOUT (Life Technologies, Burlington, ON), and $1.0 \mu \mathrm{M}$ of each primer (JV12/JV13 for EP-JV or SR33/SR46 for EP-SR) (Additional file 2: Table S1). Amplifications were performed on a DNA Dyad Engine (Bio-Rad Laboratories Ltd., Mississauga, ON) as follows: $50^{\circ} \mathrm{C}$ for $30 \mathrm{~min} ; 95^{\circ} \mathrm{C}$ for $15 \mathrm{~min}$; and $40 \mathrm{cy}$ cles of $95^{\circ} \mathrm{C}$ for $1 \mathrm{~min}, 37^{\circ} \mathrm{C}$ (EP-JV) or $50^{\circ} \mathrm{C}$ (EP-SR) for $1 \mathrm{~min}$, and $72^{\circ} \mathrm{C}$ for $1 \mathrm{~min}$, followed by a final extension of $10 \mathrm{~min}$ at $72^{\circ} \mathrm{C}$. Amplicons were resolved by $1 \%$ agarose gel electrophoresis with ethidium bromide staining. Expected sizes for EP-JV and EP-SR were 327 and $123 \mathrm{bp}$, respectively.

\section{Real-time RT-PCR}

Real-time RT-PCR was performed in duplexed reactions by combining primers and probes commonly used for GI ad GII noroviruses (Additional file 2: Table S1). Briefly, PCR amplifications were performed on a Life Technologies ABI 7500 Fast instrument in $25 \mu \mathrm{l}$ reactions consisting of: SuperScript III Platinum One-Step $1 \times$ master mix (Life Technologies), $0.2 \mu \mathrm{l}$ enzyme mix, 20U RNaseOUT, and $400 \mathrm{nM}$ of each primer and probe (Additional file 2: Table S1). Amplification conditions were as follows: $50^{\circ} \mathrm{C}$ for $30 \mathrm{~min}$; $95^{\circ} \mathrm{C}$ for $30 \mathrm{~s}$; and 45 cycles of $95^{\circ} \mathrm{C}$ for $30 \mathrm{~s}$ and $60^{\circ} \mathrm{C}$ for $1 \mathrm{~min}$. Ct values were determined using the manufacturer's software (version 2.0.5).

\section{Discordant analysis and norovirus genotyping}

Clinical sensitivity and specificity were calculated in comparison to a modified gold standard defined as concordant positive and negative results between real-time and end-point RT-PCRs (Table 2). Any discordant results were resolved by at the National Microbiology Laboratory (NML) using real-time RT-PCR with the same primers/probes but in monoplex reactions for GI and GII noroviruses (Additional file 2: Table S1). Since monoplex and duplex real-time RT-PCR targets were identical, a second reference method was also performed at the NML using RT-PCR amplification and sequencing of the norovirus major capsid protein regions $\mathrm{C}$ and $\mathrm{D}$ (Additional file 2: Table S1). The resulting sequence data was used for genotype assignment. Briefly, region $C$ and D RT-PCR reactions were performed using a One-Step RT-PCR kit (Qiagen) in $50 \mu \mathrm{l}$ reactions consisting of: $2 \mu \mathrm{l}$ enzyme, $1 \times$ buffer, $400 \mathrm{nM}$ dNTPs, 40 units of RNase Inhibitor, $10 \mu \mathrm{l}$ of template, and $500 \mathrm{nM}$ each primer (except CapB1 and CapD1 used at $1 \mu \mathrm{M}$ ) (Additional file 2: Table S1). Amplification conditions were as follows: $42^{\circ} \mathrm{C}$ for $30 \mathrm{~min} ; 95^{\circ} \mathrm{C}$ for $15 \mathrm{~min} ; 40$ cycles of $94^{\circ} \mathrm{C}$ for $30 \mathrm{~s}, 40^{\circ} \mathrm{C}$ (region $\mathrm{D}$ ) or $50^{\circ} \mathrm{C}$ (region $\mathrm{C}$ ) for $30 \mathrm{~s}$ and $72^{\circ} \mathrm{C}$ for 30s; and a final extension of $72^{\circ} \mathrm{C}$ for $10 \mathrm{~min}$. Following $2 \%$ agarose gel electrophoresis, amplicons were purified using Amicon Filter Devices (Millipore, USA) and sequencing was carried out by the Genomics Core section of the NML using primers CapA, CapB1, CapC, or CapD1.

\section{Norovirus genotyping and sequence alignments}

BioNumerics 5.1 software (Applied Maths, Austin, TX) was used to assemble consensus sequence data, pairwise and global alignments, and clustering analysis. The sequences of each region were compared to ViroNet Canada reference dataset for genotype assignment.

To compare primer/probe binding sites to the target sequences of circulating norovirus genotypes (Figure 1), sequence data was retrieved from the Genbank database on the NCBI website (www.ncbi.nlm.nih.gov) and pairwise sequence alignments were performed using the Basic Local Alignment Search Tool (BLAST) function.

\section{Quantification of noroviruses}

Norovirus genome equivalents were estimated in relation to a standard curve generated using plasmids harboring GI.4 (2008) and GII.4 (2006b) target sequences. RNA extracted from characterized stool specimens was used as template in $25 \mu \mathrm{l}$ RT-PCR reactions consisting of: $1 \mathrm{x}$ One-Step RT-PCR buffer (Qiagen), $400 \mu \mathrm{M}$ dNTPs, $0.4 \mu \mathrm{M}$ of each primer (COG1F/COG1R for GI and COG2F/COG2R for GII) (Additional file 2: Table S1), $1 \mu \mathrm{l}$ enzyme mix, and $4 \mathrm{U}$ RNaseOUT. Amplification conditions were as following: $42^{\circ} \mathrm{C}$ for $30 \mathrm{~min} ; 95^{\circ} \mathrm{C}$ for $15 \mathrm{~min}$; 45 cycles of $94^{\circ} \mathrm{C}$ for $30 \mathrm{~s}, 50^{\circ} \mathrm{C}$ for $30 \mathrm{~s}$ and $72^{\circ} \mathrm{C}$ 
for $1 \mathrm{~min}$; and a final extension of $72^{\circ} \mathrm{C}$ for $5 \mathrm{~min}$. Purified amplicons were cloned into pCR 2.1-TOPO vectors using a TOPO TA Cloning Kit according to manufacturer's instructions (Life Technologies) and inserts were confirmed by DNA sequencing on a 3130XL Genetic Analyzer (Life Technologies) at Health Canada (Ottawa, ON). Following spectrophotometric quantification, 10-fold serial dilutions of the plasmids were used as template for the real-time RT-PCR. Ct values were plotted against plasmid concentration, generating inverse linear relationships [for GI $\left(y=-3.44 x+42.13 ; \mathrm{R}^{2}=0.9995\right)$ and for GII $\left.\left(y=-3.53 x+41.63 ; R^{2}=0.9998\right)\right]$. Viral loads were expressed as $\log _{10}$ copies/ml and represent the average of triplicate values obtained in three independent experiments $(n=9)$.

\section{Statistical analysis}

Chi-square and two-tailed Fisher's exact tests were used to compare proportions in 2-by-2 contingency tables. Binomial 95\% confidence intervals and kappa statistics for each parameter were calculated by the "constant chisquare boundaries" method [45] using StatsPlus version 5.8.4.3 (AnalystSoft, Inc.).

\section{Additional files}

Additional file 1: Table S2. Retrospective analysis of gastrointestinal outbreaks in Nova Scotia.

Additional file 2: Table S1. Primer and probes used in this study $[8-11,46,47]$.

\section{Competing interests}

The authors declare that they have no competing interests.

\section{Authors' contributions}

$B R$ and $J$ carried out the specimen processing and real-time and end-point RT-PCRs. JP performed the outbreak investigations. Discrepant analysis was performed by EG and TB. OM cloned the plasmids used for viral load determination. Specificity panels were prepared by XP. TB, TH, and JL were involved in the coordination and design of the study. All authors helped draft the manuscript and the final version was approved by all authors.

\section{Acknowledgements}

We would like to thank the Nova Scotia Provincial Public Health Laboratory Network (PPHLN) for providing funding for the project and members of the Division of Microbiology at CDHA for their ongoing support. We are also indebted to the Genomic Core Section at the NML.

\footnotetext{
Author details

'Dalhousie University, Halifax, Nova Scotia, Canada. ${ }^{2}$ Division of Microbiology, Department of Pathology and Laboratory Medicine, Capital District Health Authority (CDHA), Dalhousie University, Halifax, Nova Scotia, Canada. ${ }^{3}$ Enteroviruses and Enteric Viruses Laboratory, National Microbiology Laboratory (NML), Winnipeg, Manitoba, Canada. ${ }^{4}$ Food Virology Reference Centre, Bureau of Microbial Hazards, Health Canada, Ottawa, Ontario, Canada. ${ }^{5}$ Provincial Laboratory for Public Health (ProvLab), Edmonton, Alberta, Canada. ${ }^{6}$ Department of Laboratory Medicine and Pathology, University of Alberta, Edmonton, Alberta, Canada.
}

Received: 26 March 2014 Accepted: 6 July 2014

Published: 18 July 2014

\section{References}

1. Patel MM, Widdowson MA, Glass Rl, Akazawa K, Vinje J, Parashar UD: Systematic literature review of role of noroviruses in sporadic gastroenteritis. Emerg Infect Dis 2008, 14:1224-1231.

2. Hall AJ, Vinjé J, Lopman B, Park GW, Yen C, Gregoricus N, Parashar U: Updated norovirus outbreak management and disease prevention guidelines. MMWR 2011, 60:1-15.

3. Gray JJ, Kohli E, Ruggeri FM, Vennema H, Sánchez-Fauquier A, Schreier E, Gallimore Cl, Iturriza-Gomara M, Giraudon H, Pothier P, Di Bartolo I, Inglese N, De Bruin E, van der Veer B, Moreno S, Montero V, De Llano MC, Höhne M, Diedrich SM: European multicenter evaluation of commercial enzyme immunoassays for detecting norovirus antigen in fecal samples. Clin Vaccine Immunol 2007, 14:1349-1355.

4. Bruggink LD, Witlox KJ, Sameer R, Catton MG, Marshall JA: Evaluation of the RIDAQUICK immunochromatographic norovirus detection assay using specimens from Australian gastroenteritis incidents. J Virol Methods 2011, 173:121-126.

5. Fisman DN, Greer AL, Brouhanski G, Drews SJ: Of gastro and the gold standard: evaluation and policy implications of norovirus test performance for outbreak detection. J Trans/ Med 2009, 7:23.

6. Mattison K, Grudeski E, Auk B, Brassard J, Charest H, Dust K, Gubbay J, Hatchette TF, Houde A, Jean J, Jones T, Lee BE, Mamiya H, McDonald R, Mykytczuk O, Pang X, Petrich A, Plante D, Ritchie G, Wong J, Booth TF: Analytical performance of norovirus real-time RT-PCR detection protocols in Canadian laboratories. J Clin Virol 2011, 50:109-113.

7. Mattison K, Grudeski E, Auk B, Charest H, Drews SJ, Fritzinger A, Gregoricus N, Hayward S, Houde A, Lee BE, Pang XL, Wong J, Booth TF, Vinjé J: Multicenter comparison of two norovirus ORF2-based genotyping protocols. J Clin Microbiol 2009, 47:3927-3932.

8. Ando T, Monroe SS, Gentsch JR, Jin Q, Lewis DC, Glass Rl: Detection and differentiation of antigenically distinct small round-structured viruses (Norwalk-like viruses) by reverse transcription-PCR and southern hybridization. J Clin Microbiol 1995, 33:64-71.

9. Kageyama T, Kojima S, Shinohara M, Uchida K, Fukushi S, Hoshino FB, Takeda N, Katayama K: Broadly reactive and highly sensitive assay for Norwalk-like viruses based on real-time quantitative reverse transcription-PCR. J Clin Microbiol 2003, 41:1548-1557.

10. Trujillo A, McCaustland K, Zheng D, Hadley L, Vaughn G, Adams S, Ando T, Glass R, Monroe S: Use of TaqMan real-time reverse transcriptase-PCR for rapid detection, quantification, and typing of noroviruses. J Clin Microbiol 2006, 44:1405-1412.

11. Vinjé J, Koopmans MP: Molecular detection and epidemiology of small round-structured viruses in outbreaks of gastroenteritis in the Netherlands. $J$ Infect Dis 1996, 174:610-615.

12. Kroneman A, Vega E, Vennema H, Vinjé J, White PA, Hansman G, Green K, Martella V, Katayama K, Koopmans M: Proposal for a unified norovirus nomenclature and genotyping. Arch Virol 2013, 158:2059-2068.

13. Zheng DP, Ando T, Fankhauser RL, Beard RS, Glass RI, Monroe SS: Norovirus classification and proposed strain nomenclature. Virology 2006, 346:312-323.

14. Vega E, Barclay L, Gregoricus N, Williams K, Lee D, Vinjé J: Novel surveillance network for norovirus gastroenteritis outbreaks, United States. Emerg Infect Dis 2011, 17:1389-1395.

15. Ishida S, Yoshizumi S, Ikeda T, Miyoshi M, Okano M, Okui T: Sensitive and rapid detection of norovirus using duplex TaqMan reverse transcriptionpolymerase chain reaction. J Med Virol 2008, 80:913-920.

16. Miura T, Parnaudeau S, Grodzki M, Okabe S, Atmar RL, Le Guyader FS: Environmental detection of genogroup I, II, and IV noroviruses by using a generic real-time reverse transcription-PCR assay. Appl Environ Microbiol 2013, 79:6585-6592.

17. Medici MC, Martinelli M, Ruggeri FM, Abelli LA, Bosco S, Arcangeletti MC, Pinardi F, De Conto F, Calderaro A, Chezzi C, Dettori G: Broadly reactive nested reverse transcription-PCR using an internal RNA standard control for detection of noroviruses in stool samples. J Clin Microbiol 2005, 43:3772-3778

18. Pang XL, Preiksaitis JK, Lee B: Multiplex real time RT-PCR for the detection and quantitation of norovirus genogroups I and II in patients with acute gastroenteritis. J Clin Virol 2005, 33:168-171.

19. Richards GP, Watson MA, Fankhauser RL, Monroe SS: Genogroup I and II noroviruses detected in stool samples by real-time reverse 
transcription-PCR using highly degenerate universal primers. Appl Environ Microbiol 2004, 70:7179-7184.

20. Debbink K, Lindesmith LC, Donaldson EF, Costantini V, Beltramello M, Corti D, Swanstrom J, Lanzavecchia A, Vinjé J, Baric RS: Emergence of new pandemic Gll.4 Sydney norovirus strain correlates with escape from herd immunity. $J$ Infect Dis 2013, 208:1877-1887.

21. Bull RA, Eden JS, Rawlinson WD, White PA: Rapid evolution of pandemic noroviruses of the Gll.4 lineage. PLoS Pathog 2010, 6:e1000831.

22. Centers for Disease Control and Prevention (CDC): Notes from the field: Emergence of new norovirus strain Gll.4 Sydney-United States, 2012. MMWR 2013, 62:55-55.

23. Hasing ME, Lee BE, Preiksaitis JK, Tellier R, Honish L, Senthilselvan A, Pang XL: Emergence of a new norovirus Gll.4 variant and changes in the historical biennial pattern of norovirus outbreak activity in Alberta, Canada, from 2008 to 2013. J Clin Microbiol 2013, 51:2204-2211.

24. Lee $B E$, Pang $X L$ : New strains of norovirus and the mystery of viral gastroenteritis epidemics. CMAJ 2013, 185:1381-1382.

25. Pang XL, Preiksaitis JK, Wong S, Li V, Lee BE: Influence of novel norovirus GIll.4 variants on gastroenteritis outbreak dynamics in Alberta and the Northern Territories, Canada between 2000 and 2008. PLoS One 2010, 5:e11599.

26. Van Beek J, Ambert-Balay K, Botteldoorn N, Eden JS, Fonager J, Hewitt J, Iritani N, Kroneman A, Vennema H, Vinjé J, White PA, Koopmans M, NoroNet: Indications for worldwide increased norovirus activity associated with emergence of a new variant of genotype II.4, late 2012. Euro Surveill 2013, 18:8-9.

27. Prystajecky N, Isaac-Renton J, Auk B, Fung J, Wong B, Kong C: Emergence of norovirus strain Gll.4 Sydney (2012) in BC. BCMJ 2013, 55:142-143.

28. Vega E, Barclay L, Gregoricus N, Shirley SH, Lee D, Vinjé J: Genotypic and epidemiologic trends of norovirus outbreaks in the United States, 2009-2013. J Clin Microbiol 2014, 52:147-155.

29. Di Bartolo I, Monini M, Losio MN, Pavoni E, Lavazza A, Ruggeri FM: Molecular characterization of noroviruses and rotaviruses involved in a large outbreak of gastroenteritis in Northern Italy. Appl Environ Microbiol 2011, 77:5545-5548.

30. Barrabeig I, Rovira A, Buesa J, Bartolomé R, Pintó R, Prellezo H, Domínquez A: Foodborne norovirus outbreak: the role of an asymptomatic food handler. BMC Infect Dis 2010, 10:269.

31. Johansson PJ, Torvén M, Hammarlund AC, Björne U, Hedlund KO, Svensson L: Food-borne outbreak of gastroenteritis associated with genogroup I calicivirus. J Clin Microbiol 2002, 40:794-798.

32. Lamhoujeb S, Charest H, Fliss I, Ngazoa S, Jean J: Phylogenetic analysis of norovirus isolates involved in some Canadian gastroenteritis outbreaks in 2004 and 2005. Can J Microbiol 2007, 53:1133-1140.

33. Lysén $M$, Thorhagen M, Brytting M, Hjertqvist M, Andersson $Y$, Hedlund KO Genetic diversity among food-borne and waterborne norovirus strains causing outbreaks in Sweden. J Clin Microbiol 2009, 47:2411-2418.

34. Wang D, Wu Q, Yao L, Wei M, Kou X, Zhang J: New target tissue for food-borne virus detection in oysters. Lett Appl Microbiol 2008, 47:405-409.

35. Gonin P, Couillard M, D'Halewyn MA: Genetic diversity and molecular epidemiology of Norwalk-like viruses. J Infect Dis 2000, 182:691-697.

36. Naitou H, Morita T: Selection of more appropriate PCR primer pairs for improved efficiency in detecting Norwalk-like virus (NLV) RNA. J Gen Appl Microbiol 2001, 47:241-246

37. Bok K, Abente EJ, Realpe-Quintero M, Mitra T, Sosnovtsev SV, Kapikian AZ, Green KY: Evolutionary dynamics of GII.4 noroviruses over a 34-year period. J Virol 2009, 83:11890-11901.

38. Boon D, Mahar JE, Abente EJ, Kirkwood CD, Purcell RH, Kapikian AZ, Green KY, Bok K: Comparative evolution of Gll.3 and Gll.4 norovirus over a 31-year period. J Virol 2011, 85:8656-8666.

39. Wollants $E$, Van Ranst M: Detection of false positives with a commonly used Norovirus RT-PCR primer set. J Clin Virol 2013, 56:84-85.

40. Duizer E, Pielaat A, Vennema H, Kroneman A, Koopmans M: Probabilities in norovirus outbreak diagnosis. J Clin Virol 2007, 40:38-42.

41. Plantenga MS, Shiferaw B, Keene WE, Biggs C, Terry JM, Grenz L, Cieslak PR: Specimen collection and confirmation of norovirus outbreaks. Emerg Infect Dis 2011, 17:1553-1555.

42. Kundu S, Lockwood J, Depledge DP, Chaudhry Y, Aston A, Rao K, Hartley JC, Goodfellow I, Breuer J: Next-generation whole genome sequencing identifies the direction of norovirus transmission in linked patients. Clin Infect Dis 2013, 57:407-414
43. Batty EM, Wong TH, Trebes A, Argoud K, Attar M, Buck D, Ip CL, Golubchik T, Cule M, Bowden R, Manganis C, Klenerman P, Barnes E, Walker AS, Wyllie DH, Wilson DJ, Dingle KE, Peto TE, Crook DW, Piazza P: A modified RNA-Seq approach for whole genome sequencing of RNA viruses from faecal and blood samples. PLoS One 2013, 8:e66129.

44. Finney DJ: Probit Analysis. 3rd edition. UK: Cambridge university press, Cambridge; 1971.

45. Fleiss JL, Levin B, Paik MC: Statistical Methods for Rates and Proportions. Edited by Shewart WA, Wilks SS. New York: John Wiley \& Sons; 2003. ISBN: 9780471526292.

46. Kojima S, Kageyama T, Fukushi S, Hoshino FB, Shinohara M, Uchida K, Natori K, Takeda N, Katayama K: Genogroup-specific PCR primers for detection of Norwalk-like viruses. J Virol Methods 2002, 100:107-114.

47. Vinjé J, Hamidjaja RA, Sobsey MD: Development and application of a capsid VP1 (region D) based reverse transcription PCR assay for genotyping of genogroup I and II noroviruses. J Virol Methods 2004, 116:109-117.

doi:10.1186/1743-422X-11-129

Cite this article as: Rooney et al:: Detection of circulating norovirus genotypes: hitting a moving target. Virology Journal 2014 11:129.

\section{Submit your next manuscript to BioMed Central and take full advantage of:}

- Convenient online submission

- Thorough peer review

- No space constraints or color figure charges

- Immediate publication on acceptance

- Inclusion in PubMed, CAS, Scopus and Google Scholar

- Research which is freely available for redistribution

Submit your manuscript at www.biomedcentral.com/submit
() Biomed Central 